\title{
Carotid Body Baroreceptor Preservation and Control of Arterial Pressure in Eversion Carotid Endarterectomy
}

\author{
Thomas Kotsis, MD, $\mathrm{PhD}^{1} \quad$ Panagitsa Christoforou, MD, MSc ${ }^{1}$ Konstantinos Nastos, MD, $\mathrm{PhD}^{1}$ \\ ${ }^{1}$ Vascular Unit, 2nd Department of Surgery, National and \\ Kapodistrian University of Athens Medical School, Aretaieion \\ University Hospital, Athens, Greece \\ Int J Angiol 2020;29:33-38.

\begin{abstract}
Address for correspondence Thomas Kotsis, MD, PhD, Vascular Unit, 2nd Department of Surgery, National and Kapodistrian University of Athens Medical School, Aretaieion University Hospital, 76 Vasilissis Sofias Avenue, Athens 11528, Greece

(e-mail: kotsisth@med.uoa.gr; kotsisth@otenet.gr).
\end{abstract}

\begin{abstract}
Keywords

- baroreceptor

- carotid body

- eversion carotid endarterectomy

- modified ECEA

- post carotid endarterectomy hypertension

- blood pressure
\end{abstract}

The technique of the eversion carotid endarterectomy (ECEA), as an alternative to the conventional endarterectomy with primary or patch angioplasty, is an established technique for managing internal carotid artery stenoses and recently its application has been upgraded through the European Society for Vascular Surgery guidelines (Recommendation 55: Class 1, Level A). However, the typical eversion method has been associated with postoperative hypertension due to loss of the baroreceptor reflex; the standard oblique transection at the bulb performed in the eversion endarterectomy interrupts either the baroreceptor sensoring tissue, which is mostly located in the adventitia at the medial portion of the proximal internal carotid artery, or even the proper Hering nerve, a branch of the glossopharyngeal nerve. These actions deregulate the natural negative feedback of the carotid baroreceptor. Guided by the anatomical location of the baroreceptor sensor we have elaborated a slight modification of the classical ECEA to maintain as much as possible of the viable carotid baroreceptor sensoring surface. By extending the oblique incision distal to the carotid bifurcation in the medial part of the internal carotid artery stem, an eyebrow-like part of the proximal internal carotid artery is maintained and the axis from the sensoring tissue to the nerve of Hering is protected and following the endarterectomy, postoperative arterial blood pressure levels are lower than in the classical ECEA due to the maintenance of the efficiency of the baroreceptor reflex. During the period from September 2016 to November 2018, carotid endarterectomy was performed in 57 patients. Twenty-eight of them underwent the typical ECEA and 29 patients had the modified eyebrow eversion carotid endarterectomy (me-ECEA). The changes of blood pressure baseline during the postoperative course in ECEA and me-ECEA group were analyzed and compared. Postoperative hypertension was defined as an elevation of systolic blood pressure (SBP) greater than $140 \mathrm{~mm} \mathrm{Hg}$. Patients who underwent typical ECEA had significantly higher postoperative blood pressure values compared with those who underwent me-ECEA. Actually, the mean postoperative SBP was $172.67 \pm 24.59 \mathrm{~mm} \mathrm{Hg}$ in the typical ECEA group compared with $160.86 \pm 12.83 \mathrm{~mm} \mathrm{Hg}$ in the me-ECEA group $(p=0.023)$. The mean diastolic blood pressure in the ECEA group was $65.42 \pm 11.39 \mathrm{~mm}$ $\mathrm{Hg}$ compared with $58.06 \pm 9.06 \mathrm{~mm} \mathrm{Hg}$ in the me-ECEA group $(p=0.009)$. Our proposed me-ECEA technique seems to be related to lower rates of postoperative hypertension compared with the typical ECEA, probably due to the sparing of the main mass of the baroreceptor apparatus; this improved modification (me-ECEA) of the typical eversion procedure could represent an alternative ECEA technique with its inherent advantages.
Copyright $\odot 2020$ by Thieme Medical Publishers, Inc., 333 Seventh Avenue, New York, NY 10001, USA. Tel: $+1(212)$ 760-0888.
DOI https://doi.org/ 10.1055/s-0039-3400478. ISSN 1061-1711. 
Carotid endarterectomy (CEA) is the most effective treatment of internal carotid artery (ICA) stenosis for the prevention of ischemic stroke and is beneficial in symptomatic patients and in selected asymptomatic with moderate to severe carotid artery stenosis; the maximum benefit is being observed in those with recent-onset symptoms. ${ }^{1-3}$

The eversion CEA (ECEA), performed by an experienced surgeon, is a safe, effective, and durable procedure, with many advantages: the carotid bifurcation is preserved, there is no necessity of patch, and the correction of any joined ICA kinking or coiling is feasible, while the total operative time is reduced as well as the occurrence of postoperative restenosis or formation of false anastomotic aneurysms. ${ }^{3,4}$ However, upon a successful ECEA, postoperative hypertension has been observed. These evidenced post-ECEA high levels of the arterial blood pressure (BP) have been associated with multiple and severe complications and the phenomenon is attributed to the poor functionality of the baroreceptor mechanism. ${ }^{5}$ The transection of the baroreceptor sensoring tissue leads to the interruption of the negative feedback reflex. The main mass of the baroreceptor tissue is located in the carotid body's adventitia and media, with the primary location at the medial part of the ICA stem, and these receptors consist the terminal points of the abducting fibers which through the Hering nerve run to the glossopharyngeal nerve. ${ }^{6}$ Any anatomic intervention in the carotid body/sinus region causes $B P$ fluctuations by triggering stimuli in the corresponding brain centers (brainstem) that regulate the sympathetic and parasympathetic nervous system and finally the vascular tone. In sick carotid sinus (CS), the bilateral denervation has been proposed to ameliorate the very low arterial BP levels. ${ }^{7}$ Thus, to maintain the baroreflex functionality during eversion endarterectomy, a few modifications of the typical eversion technique have been proposed, though not without associated disadvantages (-Fig. 1A-F). We propose a simple improved alteration (modified eyebrow eversion carotid endarterectomy [me-ECEA] of the typical) eversion endarterectomy with the aim to preserve as much as possible of the medial portion of the proximal internal carotid stem (eyebrow) distal to the carotid bifurcation. Obviously, the Hering nerve is preserved in any way and the initial clinical results are promising and are reported herein.

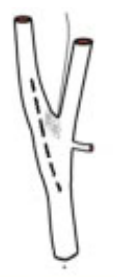

A

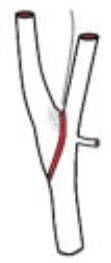

B

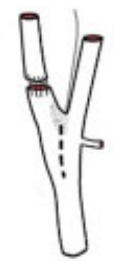

C

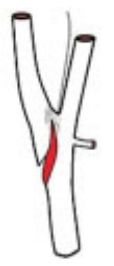

D

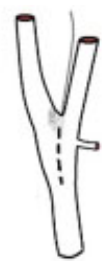

E

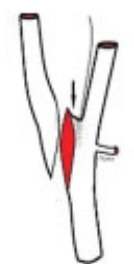

$\mathbf{F}$
Fig. 1 Types of carotid endarterectomy. (A) Standard technique (here without patch). (B) Typical eversion endarterectomy, Kasprzak and Raithel's technique 1989. (C) Chevalier's technique 1995. (D) Modified eversion endarterectomy 2017. (E) Partial eversion carotid endarterectomy 2017. (F) Our proposed technique modified eyebrow standard carotid eversion endarterectomy 2019. ${ }^{19-21}$

\section{Materials and Methods}

This work has been approved by the appropriate ethical committees of the institution in which it was performed and patients gave informed consent.

During the period from September 2016 to November 2018, CEA was performed prospectively in 57 patients. All patients were properly informed and they provided signed consent. Twenty-eight of them underwent typical ECEA and 29 patients underwent me-ECEA. We collected, analyzed, and compared the changes of BP baseline immediately and during early postoperative course in ECEA and me-ECEA groups. The hospital protocol concerning CEA dictates postoperative stay in the dedicated intensive care unit (ICU) for at least 24 hours and invasive arterial BP is monitored. Postoperative hypertension was defined as an elevation of systolic blood pressure (SBP) greater than $140 \mathrm{~mm} \mathrm{Hg}$. All patients were included in the study, regardless of concomitant diseases. Preoperative evaluation was performed by a duplex scan and digital subtraction angiography (DSA) of the supra-aortic vessels in all patients, to assess the morphological and hemodynamic characteristics of the carotid artery lesions and evaluate the risk of clamping ischemia.

Factors such as age, sex, symptoms, laterality, hypertension, diabetes, use of tobacco, and hyperlipidemia that could affect baroreceptor sensitivity were considered as a covariate in the comparative statistical analysis (-Table $\mathbf{1}$ ).

Preoperative cardiac evaluation was maintained in all patients and a baseline BP values were obtained. Before the surgery, the patient was reassessed by a cardiologist to confirm the ideal values of arterial pressure and if cardiological high arterial pressure values were observed, and then the patient

Table 1 Demographics and clinical variables of patients undergoing typical ECEA and me-ECEA

\begin{tabular}{|l|l|l|l|}
\hline Variation & & $\boldsymbol{n}$ & $\%$ \\
\hline \multirow{3}{*}{ Sex } & Male & 41 & 71.9 \\
\cline { 2 - 4 } & Female & 16 & 28.1 \\
\hline \multirow{3}{*}{ Symptoms } & Yes & 32 & 56.1 \\
\cline { 2 - 4 } & No & 25 & 43.9 \\
\hline \multirow{3}{*}{ Hypertension } & Left & 30 & 52.6 \\
\cline { 2 - 4 } & Right & 27 & 47.4 \\
\hline Diabetes & Yes history & 46 & 80.7 \\
\cline { 2 - 4 } & No history & 11 & 19.3 \\
\hline Smoking & Yes history & 19 & 33.3 \\
\cline { 2 - 4 } & No history & 38 & 66.7 \\
\hline \multirow{3}{*}{ Hyperlipidemia } & Yes history & 30 & 52.6 \\
\cline { 2 - 4 } & No history & 27 & 47.4 \\
\hline Receptors & Yes history & 50 & 87.7 \\
\cline { 2 - 4 } & No history & 7 & 12.3 \\
\hline \multirow{2}{*}{} & Yes & 29 & 50.9 \\
\cline { 2 - 4 } & No & 28 & 49.1 \\
\hline
\end{tabular}

Abbreviations: ECEA, eversion carotid endarterectomy; me-ECEA, modified eyebrow standard carotid eversion endarterectomy. 
was provided a corrected or new or additional medication to control the BP. Once the patient is transferred to the ICU, the first measured intra-arterial BP is omitted in this study, as this $\mathrm{BP}$ could be influenced by the whole process of the transportation of the patient. Next, intra-arterial BP values were recorded at 2-hour intervals until discharge from ICU, usually on the first postoperative day. Hypertension was defined as a SBP greater than $140 \mathrm{~mm} \mathrm{Hg}$ or a diastolic BP (DBP) greater than $90 \mathrm{~mm} \mathrm{Hg}$. Postoperative hypertension of SBP greater than $180 \mathrm{~mm} \mathrm{Hg}$ was defined as the requirement for acute administration of vasodilators.

\section{Statistical Analysis}

Data were collected prospectively in an electronic database. Statistical analysis was performed using GraphPad. Differences among SBP means were calculated using unpaired $t$ test. The chi-square test was used to compare differences between proportions. Differences were considered significant when the two-tailed $p$-value was less than 0.05. Multivariate logistic regression was used to determine the association between some patient characteristics and postoperative hemodynamic instability.

\section{Surgical Technique}

All patients underwent CEA performed by the same surgeon and under general anesthesia. The common carotid artery (CCA), ICA, and external carotid artery (ECA) were exposed through an oblique incision parallel to the anterior border of the sternocleidomastoid muscle. Manipulation of the carotid body at the carotid bifurcation was avoided. After intravenous administration of 5,000 IU of unfractionated heparin, the ICA, CCA, and ECA were clamped. No use of shunt placement was needed in two groups of surgical technique. In the first group, the surgeon performed the typical ECEA following the typical oblique transection just lateral to the end of the Hering nerve. In the second group, the surgeon performed me-ECEA. The ICA was obliquely transected at the level of the carotid bulb with a big Pott's scissor initiating a curving division from the CCA (caudal corner) toward the lateral aspect of the carotid bifurcation, maintaining a conical rim of the medial portion of the proximal ICA with a rich conical brim (at least 6-8 $\mathrm{mm}$ ) at the distal (cephalad) corner. Thus, a roll around the edge of the proximal ICA tissue is left behind with much of its medial portion where the baroreceptors are nested. This way, a lot of the sensing interface of the bulb and the proximal carotid artery is spared and can be functional maintaining its ability to transmit the dilatation of the vessel following the repair. The complete transection of the ICA allowed a perfect eversion endarterectomy of the ICA to be performed. The eversion endarterectomy of the proximal ICA rim, the bulb, the proximal ECA, and the distal CCA followed. The everted ICA was brought down to its normal anatomic position and flushed with heparinizes solution, allowing the later removal of any remaining flowing tears. When substantial atherosclerotic disease extended into the distal CCA, a longitudinal arteriotomy of the CCA was extended caudally, and endarterectomy continued. Subsequently, the ICA was reanastomosed with running suturing (polypropylene 6.0) to the central bifurca- tion, starting from the cephalad corner with small bites and with a second knot at the caudal corner. The anastomosis was "inflated" with blood before the final closing of the knot, and any bleeding points due to this action were sealed using isolated stitches with polypropylene 7.0.

\section{Results}

Demographics and clinical data are listed in - Table 1. Most of the patients who underwent e-CEA and were included in the study were men (71.9\%), while only $28.1 \%$ were women. More than half of the patients $(56.1 \%)$ had preoperative symptoms such as ischemic stroke or transient ischemic stroke with carotid stenosis over $70 \%$, while $43.9 \%$ were asymptomatic patients with a high internal carotid stenosis above $80 \%$ and with coexisting stenosis of the contralateral ICA. In $52.6 \%$ of the cases, the operated carotid artery was the left one. More than three-quarters of the patients (80.7\%) had a history of arterial hypertension and were receiving antihypertensive therapy, while a very small percentage of patients (19.3\%) had no arterial hypertension and had not taken relevant medication. All patients had satisfactory preoperative BP values. One-third of the patients (33.3\%) had type 2 diabetes, treated with antidiabetic tablets or insulin, while $66.7 \%$ of patients had no history of diabetes. Almost all patients $(87.7 \%)$ had hyperlipidemia under medical treatment. There was no significant difference concerning the use of tobacco; 30 patients were smokers, while 27 patients were not. In $50.9 \%$ of the patients, me-ECEA was performed and the baroreceptors were maintained (-Fig. 1E), while the other half underwent the typical ECEA. All the surgical procedures were performed by the same senior surgeon.

Each parameter in - Tables $\mathbf{2}$ and $\mathbf{3}$ was studied on the basis of the preservation of the receptor or not. According to recorded data and statistical analysis ( - Table 2), sex distribution was equal in both groups, while symptoms and laterality had statistically significant difference between the two groups. In the typical ECEA group, 10 (35.7\%) patients were asymptomatic and 18 (64.3\%) were symptomatic, while in the meECEA group, 22 (75.9\%) were asymptomatic and only 7 patients (24.1\%) were symptomatic $(p=0.02)$. In the group of patients using the technique of the typical ECEA, the removed lesion was at the left carotid in 19 (67.9\%) patients and at the right in only $9(32.1 \%)$ patients, while in the me-ECEA group the percentages are 37.9 and 62.1 , respectively $(p=0.024)$. At the time of enrolment, six (20.7\%) patients in the typical EC group and five (17.9\%) patients in the me-ECEA group had a history of hypertension therapy $(p=0.78)$. There was no significant difference between the two groups $(p=0.708)$, concerning the diabetes mellitus. Also, there were no significant difference between the two groups concerning smoking $(p=0.696)$ or hyperlipidemia $(p=0.650)$.

However, the patients who underwent the typical ECEA had significantly higher postoperative BP values compared with those who underwent me-ECEA.

Actually, the mean postoperative SBP was $172.67 \pm$ $24.59 \mathrm{~mm} \mathrm{Hg}$ in the typical ECEA group compared with $160.86 \pm 12.83 \mathrm{~mm} \mathrm{Hg}$ in the me-ECEA group $(p=0.023)$. 
Table 2 Demographics and clinical variables of patients undergoing typical ECEA and me-ECEA, based on the presence of baroreceptors or not during surgical procedure

\begin{tabular}{|l|l|l|l|l|}
\hline Variable & & Receptors & No receptors & $p$ \\
\hline \multirow{5}{*}{ Sex } & Male & $20 / 41(69 / 71.9 \%)$ & $21 / 41(75 / 71.9 \%)$ & 0.612 \\
\cline { 2 - 5 } & Female & $\begin{array}{l}9 / 16 \\
(31 / 28.1 \%)\end{array}$ & $7 / 16(25 / 28.1 \%)$ & \\
\hline \multirow{3}{*}{ Symptoms } & Asymptomatic & $22 / 32(75.9 / 56.1 \%)$ & $10 / 32(35.7 / 56.1 \%)$ & 0.002 \\
\cline { 2 - 5 } & Symptomatic & $7 / 25(24.1 / 43.9 \%)$ & $18 / 25(64.3 / 43.9 \%)$ & \\
\hline \multirow{3}{*}{ Hypertensiity } & Left & $11 / 30(37.9 / 52.6 \%)$ & $19 / 30(67.9 / 52.6 \%)$ & 0.024 \\
\cline { 2 - 5 } & Right & $18 / 27(62.1 / 47.4 \%)$ & $9 / 27(32.1 / 47.4 \%)$ & \\
\hline \multirow{3}{*}{ Diabetes } & No history & $23 / 46(79.3 / 80.7 \%)$ & $23 / 46(82.1 / 80.7 \%)$ & 0.786 \\
\cline { 2 - 5 } & Yes history & $6 / 11(20.7 / 19.3 \%)$ & $5 / 11(17.9 / 19.3 \%)$ & \\
\hline \multirow{3}{*}{ Smoking } & No history & $9 / 19$ & $10 / 19(35.7 / 33.3 \%)$ & 0.708 \\
\cline { 2 - 5 } & Yes history & $(31 / 33.3 \%)$ & $18 / 38(64.3 / 66.7 \%)$ & \\
\hline Hyperlipidemia & No history & $16 / 38(69 / 66.7 \%)$ & $14 / 30(50 / 52.6 \%)$ & 0.696 \\
\cline { 2 - 5 } & Yes history & $13 / 27(44.8 / 47.4 \%)$ & $14 / 27(50 / 47.4 \%)$ & \\
\cline { 2 - 5 } & No history & $26 / 50(89.7 / 87.7 \%)$ & $24 / 50(85.7 / 87.7 \%)$ & 0.650 \\
\cline { 2 - 5 } & Yes history & $3 / 7$ & $4 / 7(14.3 / 12.3 \%)$ & \\
\hline
\end{tabular}

Abbreviations: ECEA, eversion carotid endarterectomy; me-ECEA, modified eyebrow standard carotid eversion endarterectomy.

The mean DBP in the ECEA group was $65.42 \pm 11.39 \mathrm{~mm} \mathrm{Hg}$ compared with $58.06 \pm 9.06 \mathrm{~mm} \mathrm{Hg}$ in the me-ECEA group $(p=0.009)$. Furthermore, none of the factors, such as age ( $p=0.69)$, height $(p=0.96)$, weight $(p=0.58)$, or body mass index (BMI; $p=0.36$ ) appeared to be statistically significant either in the first group or the second one, and did not affect the outcome of arterial pressure.

There were no postoperative complications, such as death, myocardial infarction, atrial fibrillation, wound hematoma, transient ischemic attack, and minor or major stroke. No required reintervention was performed. All the patients were discharged from the hospital on the second or third postoperative day.

\section{Discussion}

Although the technique of the ECEA is not new, only recently its application is proposed in the European Society for Vascular Surgery guidelines with the recommendation 55, Class I with A level of evidence. ${ }^{3}$ This technique was originally presented by DeBakey in 1957 and others in 1959 (-Fig. 1A) and modified in 1989 by Kasprzak and Raithel ${ }^{4}$ (-Fig. 1B). The main concern related to the eversion endarterectomy is the possible cephalad extension of the atherosclerotic plaque outside surgical limits; a short intervening 5-mm PTFE jump graft is one of the several solutions proposed by many authors for distal intimal fixation. However, the most obvious advantage of the eversion technique is that following the plaque removal, two elliptical vessel tissues are anastomosed at a level of maximum diameter of the ICA, permitting large vessel area at the level of the anastomosis with maintenance of the bifurcation geometry. Other important benefits are the optimum correction of the
ICA and reduction of surgical time, the possibility of aneurysm' s development by use of venous patch, the contamination after synthetic patch use, as well as the restenosis rate. $^{3,8-10}$ The typical ECEA includes the oblique transection of the internal carotid to the carotid bifurcation, the removal of the atherosclerotic plaque by the inverse technique from the internal carotid and the region of the bifurcation or more caudally, and the reimplantation of the internal carotid into the central stump.

However, this advantageous oblique transection of the internal carotid stem at the level of the carotid bifurcation (which is the typical established ECEA) unfortunately destroys the baroreceptor continuity, as most of this sensitive tissue lies at the adventitia of the proximal ICA at the medial portion adjacent to the nerve of Hering which collects transmissions from the baroreceptors. In 1924, Hering discovered that these baroreceptors were located in the CS. ${ }^{5,11-13}$

The CS is a dilatation in the carotid bifurcation usually at the origin of the proximal ICA. The most common site is the origin of the ICA, in $74.3 \%$, but the CS can also be found in the distal part of the CCA inferior to the bifurcation and it contains baroreceptors that influence BP. Any variation in the location of the CS is very important in the case of CEA. The patient's hemodynamic status can change dramatically when the stimulation of the CS baroreceptors is affected during surgical interventions or/and postoperative, causing serious complications. Endovascular or surgical carotid interventions affect this complicated control system and the postinterventional BP behavior. ${ }^{14}$ For this, following a repair of a carotid stenosis, the patients should be monitored, due to the fact that BP events frequently occur immediately after intervention. ${ }^{15}$ The complications of postendarterectomy hypertension can be serious 
Table 3 Demographics, clinical, and arterial pressure variables of patients undergoing typical ECEA and me-ECEA based on the presence of baroreceptors or not during surgical procedure

\begin{tabular}{|c|c|c|c|c|}
\hline Variable & Receptors & Mean & $\begin{array}{l}\text { Standard } \\
\text { deviation }\end{array}$ & $p$ \\
\hline \multirow[t]{2}{*}{ Age } & Yes & 69.45 & 8.343 & 0.691 \\
\hline & No & 70.25 & 6.681 & \\
\hline \multirow[t]{2}{*}{ Height } & Yes & 168.72 & 7.526 & 0.966 \\
\hline & No & 168.64 & 6.573 & \\
\hline \multirow[t]{2}{*}{ Weight } & Yes & 76.21 & 12.347 & 0.588 \\
\hline & No & 77.82 & 9.840 & \\
\hline \multirow[t]{2}{*}{$\mathrm{BMI}$} & Yes & 26.546 & 3.872 & 0.367 \\
\hline & No & 27.486 & 3.9278 & \\
\hline \multirow{2}{*}{$\begin{array}{l}\text { Median } \\
\text { systolic } \\
\text { pressure }\end{array}$} & Yes & 140.258 & 10.816 & 0.014 \\
\hline & No & 148.60 & 13.970 & \\
\hline \multirow{2}{*}{$\begin{array}{l}\text { Median } \\
\text { diastolic } \\
\text { pressure }\end{array}$} & Yes & 67.051 & 11.037 & 0.183 \\
\hline & No & 71.017 & 11.190 & \\
\hline \multirow{2}{*}{$\begin{array}{l}\text { Maximum } \\
\text { systolic } \\
\text { pressure }\end{array}$} & Yes & 160.862 & 12.838 & 0.023 \\
\hline & No & 172.678 & 24.590 & \\
\hline \multirow{2}{*}{$\begin{array}{l}\text { Minimum } \\
\text { systolic } \\
\text { pressure }\end{array}$} & Yes & 121.965 & 12.935 & 0.218 \\
\hline & No & 126.392 & 13.876 & \\
\hline \multirow{2}{*}{$\begin{array}{l}\text { Maximum } \\
\text { diastolic } \\
\text { pressure }\end{array}$} & Yes & 75.931 & 12.875 & 0.521 \\
\hline & No & 77.964 & 10.768 & \\
\hline \multirow{2}{*}{$\begin{array}{l}\text { Minimum } \\
\text { diastolic } \\
\text { pressure }\end{array}$} & Yes & 58.069 & 9.063 & 0.009 \\
\hline & No & 65.428 & 11.393 & \\
\hline
\end{tabular}

Abbreviations: ECEA, eversion carotid endarterectomy; me-ECEA, modified eyebrow standard carotid eversion endarterectomy.

and hyperperfusion syndrome, atrial fibrillation, or myocardial infarction can occur.

Thus, to maintain the baroreceptor reflex function during the eversion endarterectomy, a few modifications of the typical ECEA technique have been proposed, though not without disadvantages (-Fig. 1A-F). In 1995, Reigner and colleagues ${ }^{16}$ proposed Chevalier's surgical technique ( - Fig. 1C); a complete oblique transection of distal ICA downstream from the plaque and longitudinal arteriotomy of the CCA are performed, extended to the origin of the ECA. The technique protects the carotid body fibers without altering the sensitivity of the baroreceptors. However, while this method allows the complete peripheral carotid eversion endarterectomy, at the same time it requires two arteriotomies, and the anatomical character of the eversion endarterectomy is disturbed, since two circular vessels are anastomosed, instead of two elliptical vessels. The restenosis at the level of the internal end-to-end anastomosis is anticipated to be higher.

In the same year, Musicant et al described a similar technique of modified ECEA, involving a longitudinal arteriotomy limited to the carotid bulb, without transection of the
ICA (-Fig. 1D). The incision of ICA includes anterior and posterior wall and the removal of the plaque is performed as in the prior technique; the atheroma is removed though the vessel till the distal part of the plaque. Also, we assume that the whole plaque cannot safely be removed, as there is also the probability of remaining distal flaps that may lead to carotid dissection or carotid thrombosis. ${ }^{17}$

McBride et al recently described a modified technique ( - Fig. 1E) for performing eversion endarterectomy called partial eversion carotid endarterectomy with advantages

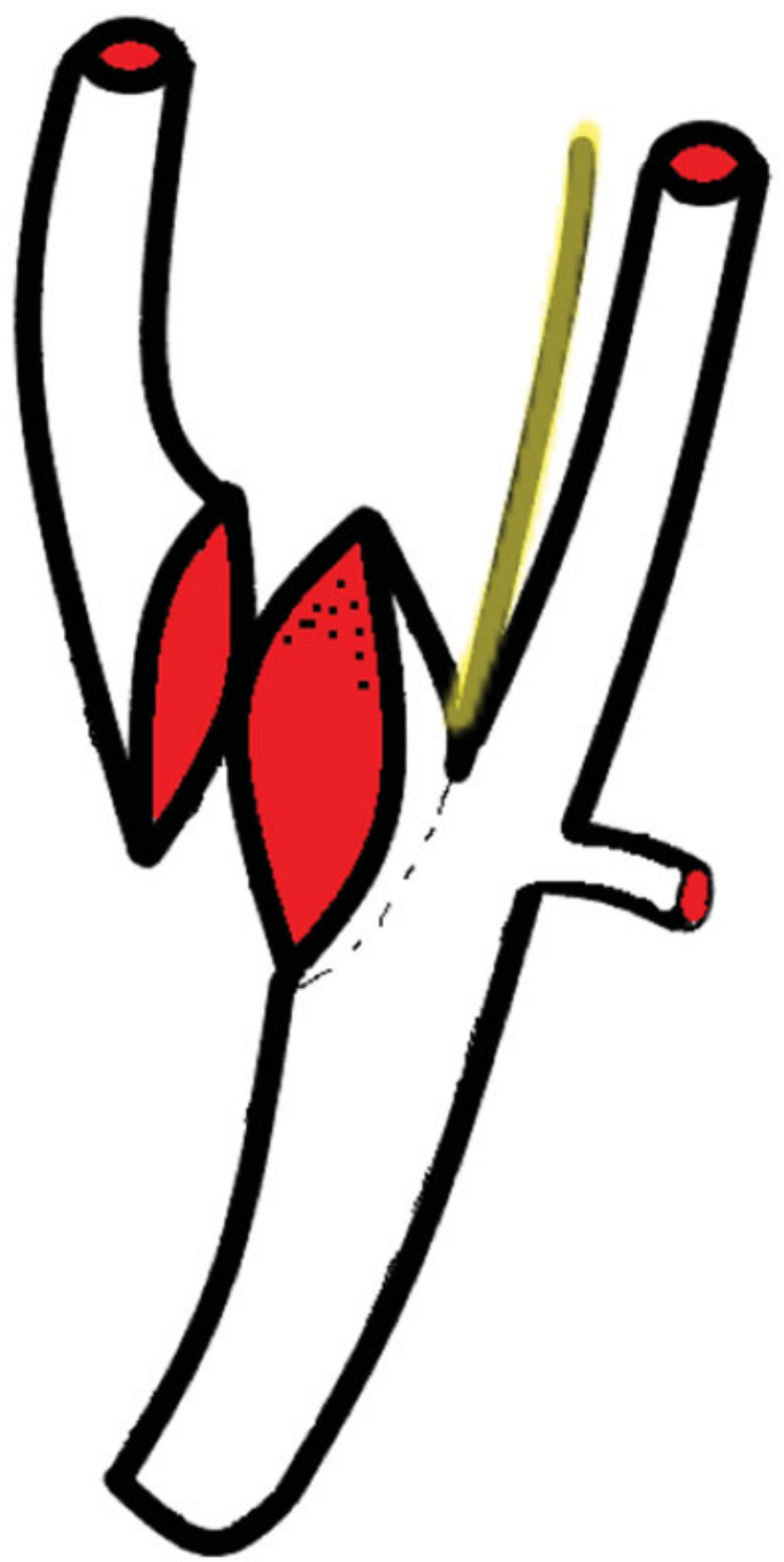

Fig. 2 The modified eyebrow standard carotid eversion endarterectomy technique is our preferable method for repairing internal carotid artery stenosis in symptomatic and asymptomatic patients, by extending the oblique incision distal to the carotid bifurcation in the medial part of the internal carotid artery and a stem like an eyebrow of the proximal internal carotid artery is maintained and the axis from the sensoring tissue to the nerve of Hering is protected following the endarterectomy. 
such as reduction of operative and carotid clamping time and avoiding the use of patch closure. This method uses an oblique anterior wall arteriotomy at the carotid bifurcation, allowing partial eversion of the vessel before an endarterectomy is performed. With this technique, the complete removal of the atherosclerotic plaque is not ensured, because the intraoperative peripheral extension of plaque is difficult to be assessed and accessed. ${ }^{18}$

Our preferable surgical method for the treatment of carotid artery stenosis is the ECEA and to spare the baroreflex functionality we suggest an improved me-ECEA (- Fig. 1F), involving a full oblique incision of the proximal ICA at the carotid bifurcation, but retaining a small truncation of the ICA to leave intact much of the baroreceptors nested at the adventitia of the medial portion of the proximal ICA. This eyebrow-like conical proximal ICA rim allows the continuity of the negative feedback mechanism, preventing the postoperative hypertension and its consequences. We have designed this prospective study and our results show that following the me-ECEA technique, the efficiency of baroreceptors is maintained to a great degree, at least resulting in significantly lower arterial BP levels in the immediate postoperative time compared with the typical ECEA technique, without losing any of the advantages of the iconic ECEA. A drawback of this study is the small number of patients; however, the difference of arterial BP between the two groups is statistically significant. More studies adopting the simple me-ECEA technique are welcome to support our thesis. The me-ECEA technique is our preferable method for repairing ICA stenosis in symptomatic and asymptomatic patients (-Fig. 2).

\section{Conclusion}

The me-ECEA is accompanied by lower rates of postoperative hypertension comparing to the typical ECEA, a fact probably ought to the sparing of much of baroreceptor sensing surface and apparatus. We propose this simple procedure as an improved ECEA technique with the ECEA inherent advantages, and the additional efficient inhibition of immediate postoperative hypertension, commonly observed in the typical ECEA.

\section{Conflict of Interest}

None.

\section{References}

1 Halliday A, Mansfield A, Marro J, et al; MRC Asymptomatic Carotid Surgery Trial (ACST) Collaborative Group. Prevention of disabling and fatal strokes by successful carotid endarterectomy in patients without recent neurological symptoms: randomised controlled trial. Lancet 2004;363(9420):1491-1502

2 Newman JE, Bown MJ, Sayers RD, et al. Post-carotid endarterectomy hypertension. Part 2: Association with peri-operative clinical, anaesthetic, and transcranial Doppler derived parameters. Eur J Vasc Endovasc Surg 2017;54(05):564-572
3 Naylor AR, Ricco JB, de Borst GJ, et al; ESVS Guidelines Committee; ESVS Guideline Reviewers. Editor's choice - management of atherosclerotic carotid and vertebral artery disease: 2017 Clinical Practice Guidelines of the European Society for Vascular Surgery (ESVS). Eur J Vasc Endovasc Surg 2018;55(01):3-81

4 Davidovic L, Tomic I, Markovic D, et al. Carotid Endarterectomy: eversion technique. J US-China Med Sci 2015;12:99-104. doi: 10.17265/1548-6648/2015.03.002

5 Demirel S, Goossen K, Bruijnen H, Probst P, Böckler D. Systematic review and meta-analysis of postcarotid endarterectomy hypertension after eversion versus conventional carotid endarterectomy. J Vasc Surg 2017;65(03):868-882

6 Toorop RJ, Ousrout R, Scheltinga MR, Moll FL, Bleys RL. Carotid baroreceptors are mainly localized in the medial portions of the proximal internal carotid artery. Ann Anat 2013;195(03):248-252

7 Taurino M, Filippi F, Persiani F, et al. Hemodynamic changes in Chevalier eversion versus conventional carotid endarterectomy. Eur J Vasc Endovasc Surg 2014;48(05):514-520

8 Cao P, Giordano G, De Rango P, et al. Eversion versus conventional carotid endarterectomy: late results of a prospective multicenter randomized trial. J Vasc Surg 2000;31(1, Pt 1):19-30

9 Schneider JR, Helenowski IB, Jackson CR, et al; Society for Vascular Surgery Vascular Quality Initiative and the Mid-America Vascular Study Group. A comparison of results with eversion versus conventional carotid endarterectomy from the Vascular Quality Initiative and the Mid-America Vascular Study Group. J Vasc Surg 2015;61(05):1216-1222

10 Paraskevas KI, Robertson V, Saratzis AN, Naylor AR. Editor's choice - an updated systematic review and meta-analysis of outcomes following eversion vs. conventional carotid endarterectomy in randomised controlled trials and observational studies. Eur J Vasc Endovasc Surg 2018;55(04):465-473

11 Zimmer HG. Heinrich Ewald Hering and the carotid sinus reflex. Clin Cardiol 2004;27(08):485-486

12 Shoja MM, Rai R, Lachkar S, et al. The carotid sinus nerve and the first English translation of Hering's original research on this nerve. Cureus 2019;11(01):e3898

13 Porzionato A, Macchi V, Stecco C, De Caro R. The carotid sinus nerve-structure, function, and clinical implications. Anat Rec (Hoboken) 2019;302(04):575-587

14 West CT, Brassett C, Gaunt ME. Variations in carotid sinus anatomy and their relevance to carotid interventions. Folia Morphol (Warsz) 2018;77(04):693-697

15 Hirschl M, Kundi M. Carotid interventions and blood pressure. Wien Med Wochenschr 2014;164(23-24):503-507

16 Reigner B, Reveilleau P, Gayral M, Papon X, Enon B, Chevalier JM. Eversion endarterectomy of the internal carotid artery: midterm results of a new technique. Ann Vasc Surg 1995;9(03):241-246

17 Musicant SE, Guzzetta VJ, Terramani TT, et al. Modified eversion carotid endarterectomy (mECEA): analysis of clinical and financial outcomes. Ann Vasc Surg 2017;42:16-24

18 McBride R, Porter J, Al-Khaffaf H. The modified operative technique of partial eversion carotid endarterectomy. J Vasc Surg 2017;65(01):263-266

19 Kiney R, Hirsch D, Seiller C, Thiranos JS, Petit H. Does carotid eversion endarterectomy and reimplantation reduce the risk of restenosis? Ann Vasc Surg 1993;7(05):407-413

20 Kasprzak P, Raithel D. Eversion endarterectomy for internal carotid artery. Vasa Suppl 1992;37:83-84

21 Vanamale R, Van Schil P, De Maeseneer M. Closure of the internal carotid artery after endarterectomy: the advantages of patch angioplasty without its disadvatages. Ann Vasc Surg 1990;4(01):81-84 